\title{
Novel 3D scaffolds of chitosan-PLLA blends for tissue engineering applications: Preparation and characterization
}

\author{
Ana Rita C. Duarte ${ }^{\mathrm{a}, \mathrm{b}, *}$, João F. Mano ${ }^{\mathrm{a}, \mathrm{b}}$, Rui L. Reis ${ }^{\mathrm{a}, \mathrm{b}}$ \\ a 3B's Research Group - Biomaterials, Biodegradables and Biomimetics, Dept. of Polymer Engineering, University of Minho, Headquarters of the European Institute of \\ Excellence on Tissue Engineering and Regenerative Medicine, AvePark, Zona Industrial da Gandra, S. Cláudio do Barco, 4806-909 Caldas das Taipas, Guimarães, Portugal ${ }^{1}$ \\ ${ }^{\mathrm{b}}$ IBB - Institute for Biotechnology and Bioengineering, PT Associated Laboratory (Laboratório Associado), Portugal ${ }^{2}$
}

\section{A R T I C L E I N F O}

\section{Article history:}

Received 12 January 2010

Received in revised form 16 May 2010

Accepted 23 May 2010

\section{Keywords:}

Chitosan

Poly(L-lactic acid)

Supercritical fluids

Scaffolds

Tissue engineering

\begin{abstract}
A B S T R A C T
This work addresses the preparation of 3D porous scaffolds of blends of chitosan and poly(L-lactic acid), CHT and PLLA, using supercritical fluid technology. Supercritical assisted phase-inversion was used to prepare scaffolds for tissue engineering purposes. The physicochemical and biological properties of chitosan make it an excellent material for the preparation of drug delivery systems and for the development of new biomedical applications in many fields from skin to bone or cartilage regeneration. On the other hand, PLLA is a synthetic biodegradable polymer widely used for biomedical applications. Supercritical assisted phase-inversion experiments were carried out in samples with different polymer ratios and different polymer solution concentrations. The effect of CHT:PLLA ratio and polymer concentration and on the morphology and topography of the scaffolds was assessed by SEM and Micro-CT. Infra-red spectroscopic imaging analysis of the scaffolds allowed a better understanding on the distribution of the two polymers within the matrix. This work demonstrates that supercritical fluid technology constitutes a new processing technology, clean and environmentally friendly for the preparation of scaffolds for tissue engineering using these materials.
\end{abstract}

(c) 2010 Elsevier B.V. All rights reserved.

\section{Introduction}

Chitosan (CHT) is a natural polymer, biodegradable and biocompatible, comprised of $\beta(1 \rightarrow 4)$-glucosamine and $\mathrm{N}$-acetyl$\mathrm{D}$-glucosamine units. It is a cationic polymer derived from chitin, which is widely found in shells of crustaceous such as crabs and shrimps and it is the second most abundant polymer after cellulose. The physicochemical and biological properties of chitosan make it an excellent material for the preparation of drug delivery systems and for the development of new biomedical applications in many fields from skin to bone or cartilage $[1,2]$. The main disadvantage of the use of chitosan for the production of scaffolds is related to its poor mechanical properties. Nonetheless, chitosan has been processed in different forms to be used in tissue engineering applications [3-6] and as a drug delivery vehicle [7-10]. The preparation of these systems normally involves freeze-drying or lyophiliz-

\footnotetext{
* Corresponding author at: 3B's Research Group - Biomaterials, Biodegradables and Biomimetics, Dept. of Polymer Engineering, University of Minho, Headquarters of the European Institute of Excellence on Tissue Engineering and Regenerative Medicine, AvePark, Zona Industrial da Gandra, S. Cláudio do Barco, 4806-909 Caldas das Taipas, Guimarães, Portugal. Tel.: +351 253510 900; fax: +351 253510909.

E-mail address: aduarte@dep.uminho.pt (A.R.C. Duarte).

1 www.ibb.pt.

2 http://www.3bs.uminho.pt.
}

ing a chitosan gel solution using diluted acetic acid solutions $[11,12]$.

On the other hand, many biodegradable, synthetic polymers, namely polyesters including poly(L-lactic acid), poly(glycolic acid) and their copolymers have been used in the production of scaffolds [13-15]. Poly(L-lactic acid) (PLLA), exhibits good mechanical properties and it is easily processable. However, as a major drawback it can elicit undesirable inflammatory and allergenic reactions [16] because of the decrease in the local $\mathrm{pH}$ as a consequence of its hydrolytic degradation.

The combination of a natural polymer, such as chitosan with the synthetic PLLA might overcome some of the drawbacks of the polymers alone and lead to a material with interesting characteristics to be used in the biomedical field. The production of a homogeneous polymeric blend of chitosan and poly(L-lactic acid) is, however, very difficult to achieve. Melt based technologies are not suitable for chitosan processing due to the high $T_{\mathrm{g}}$ of chitosan. Therefore, chitosan will decompose before melting. Solvent-based methodologies present a more appropriate solution. Nonetheless, major problems come up in the choice of a solvent able to dissolve chitosan and poly(L-lactic acid). Dilute acid solutions are known to be good solvents for chitosan, whereas some organic solvents are able to dissolve PLLA. An approach that has been followed is a two step procedure for the preparation of composite scaffolds. Jiao et al. reported the fabrication of PLLA-chitosan composite sponges, 
Table 1

Summary of the supercritical assisted phase-inversion experiments carried out.

\begin{tabular}{lccl}
\hline Experiment \# & Chitosan (\%) & PLLA (\%) & $\begin{array}{l}\text { Polymer solution } \\
\text { concentration (wt.\%) }\end{array}$ \\
\hline 1 & 100 & 0 & 2 \\
2 & 100 & 0 & 5 \\
3 & 75 & 25 & 2 \\
4 & 50 & 50 & 2 \\
5 & 25 & 75 & 2 \\
6 & 0 & 100 & 5 \\
\hline
\end{tabular}

with potential applications in tissue engineering [17]. In this work, a PLLA foam was initially prepared by solution casting and particulate leaching, using dichloromethane as solvent and $\mathrm{NaCl}$ as porogen. In a subsequent step, the foam is immersed in a chitosan solution, which is freeze-dryed. Our research group has also reported the preparation of PLLA/CHT hybrid scaffolds by the deposition of CHT onto the pore walls of PLLA construct in order to form a micro-structured low dense foam inside previously prepared PLLA scaffolds [6,7].

The challenge arises, therefore, in the preparation of a homogeneous blend. Chen et al. reported the successful precipitation of PLLA-chitosan blends from a DMSO:acetic acid solution in acetone [18]. In their work, different compositions were prepared and characterized. The preparation of biodegradable blend membranes has been reported in a work from Wan $[19,20]$, in which membranes are casted from a dilute acetic acid solution + acetone (or DMSO). The authors further report this procedure in the preparation of 3D porous matrixes [21].

Besides the difficulties encountered to find the appropriate technology for processing chitosan-PLLA blends, the melt- and solvent-based techniques present inherent disadvantages, such as the use of high temperatures and organic solvents, respectively. Products for human consumption are being rigorously controlled by international safety regulations, thus it is necessary to warrant the complete removal and absence of organic solvents. Supercritical fluid technology appears to be, therefore an interesting alternative to the traditional processing methods [22-25].

Supercritical assisted phase-inversion was initially proposed by Matsuyama et al. [26] and Reverchon and Cardea [27] for the preparation of thin polymeric membranes. It has also been reported for the processing natural based polymers, namely, a polymeric blend of starch and poly(L-lactic acid) from a chloroform solution was processed [28]. Temtem et al. reported the precipitation of chitosan membranes from an aqueous solution of dilute acetic acid [29]. Recently, the feasibility of processing chitosan from organic solutions has also been described and the effect of different organic solvents on the morphology of the scaffolds obtained was accessed [30].

The supercritical assisted phase-inversion process involves casting of a polymer solution onto an inert support followed by immersion of the support with the cast film into a high-pressure vessel, which is filled with a non-solvent for the polymer. The contact between the solvent and the non-solvent causes the solution to be phase-separated. In the case of the supercritical assisted phaseinversion process the most commonly used non-solvent is carbon dioxide. This fact adds some advantages over the conventional immersion precipitation process, as simply by tuning the process conditions, i.e. pressure and temperature, one can tailor the final structure of the product. Additionally, when carbon dioxide is used as a non-solvent a subsequent drying step is avoided and the porous structure obtained is a dry product free of any residual solvent. Even though the polymer is initially dissolved in an organic solution, it is a very small amount and, further, the use of supercritical carbon dioxide $\left(\mathrm{scCO}_{2}\right)$ allows complete solvent removal as it has good diffusivity and mass transfer properties. The ability of carbon dioxide to diffuse and penetrate in the bulk of the 3D matrix guarantees the complete extraction of the organic solvent [31].

In this work, the possibility of processing a homogeneous blend of chitosan-PLLA using supercritical fluid technology was evaluated and the scaffolds obtained were characterized by different techniques.

\section{Experimental procedure}

\subsection{Materials}

Chitosan of medium molecular weight (CAS 9012-76-4, degree of deacetylation $\sim 85 \%$ ), was purchased from Aldrich. Poly(L-lactic acid) (PLLA) of high stereoregularity $(\mathrm{Mn}=69,000, \mathrm{Mw} / \mathrm{Mn}=1.734)$ was obtained from Cargill Dow Polymer. Acetic acid, (CAS 6419-7, 99.7\% purity) and chloroform, (CAS 67-68-5, 99.9\% purity) were purchased from Panreac and Vaz Pereira, respectively. Carbon dioxide (99.5\%, industrial grade) was obtained from Air Liquide. Chitosan was previously purified using a protocol described elsewhere [32]. All the other products were used with no further purification.

\subsection{Supercritical assisted phase-inversion process}

The phase-inversion experiments were carried out in an apparatus especially for this purpose and presented in a previous work [26].

Chitosan is mixed with PLLA and dissolved in acetic acid + chloroform in order to achieve a $2 \mathrm{wt}$.\% polymeric solution. This procedure was performed separately for each of the ratios of CHT:PLLA (75:25, 50:50 and 25:75 (w/w)). Additionally, a solution of pure chitosan (2 and $5 \mathrm{wt. \%}$ ) and pure PLLA ( $5 \mathrm{wt} . \%$ ) were also prepared (Table 1 ).

In each experiment a small amount (ca. $2 \mathrm{ml}$ ) of the polymer solution is loaded in a stainless steel cap with $2 \mathrm{~cm}$ diameter, which is placed inside the high-pressure vessel. The vessel is heated in by means of an electric thin band heater (OGDEN) connected to a temperature controller, that maintains temperature within $\pm 1^{\circ} \mathrm{C}$. Carbon dioxide is pumped into the vessel using high-pressure piston pump (P-200A Thar Technologies) until the operational pressure is attained. The pressure inside the vessel is measured with a pressure transducer. The system was closed for $45 \mathrm{~min}$ to allow the occurrence of phase separation. Afterwards the system is flushed for another $45 \mathrm{~min}$, with a stream of carbon dioxide at very low flow rate $(5 \mathrm{~g} / \mathrm{min})$, in order to ensure complete drying of the scaffolds. The flow is regulated by a flow meter (Siemens, SITRANS FC MASS FLO MASS2100).

\subsection{Scaffold characterization}

Scanning Electron Microscopy (SEM): Samples of the scaffolds prepared were observed by a Leica Cambridge S360 Scanning Electron Microscope. The samples were fixed by mutual conductive adhesive tape on aluminium stubs and covered with gold palladium using a sputter coater.

Micro-Computed Tomography ( $\mu$-CT): The inner structure, porosity and interconnectivity were evaluated by micro-computerized tomography using a Micro-CT scanner (Skyscan 1702, Belgium) with penetrative X-rays of $40 \mathrm{keV}$. The X-ray scans were acquired in high-resolution mode. CT Analyser ${ }^{\circledR}$ software was used to visualize and reconstruct the 2D X-ray sections images of the scaffolds.

Fourier Transformed Infra-Red analysis (FTIR analysis) was performed to the pure chitosan and PLLA matrixes as well as to the polymeric blends. Spectra were recorded at 32 scans with a resolution of $2 \mathrm{~cm}^{-1}$ (Shimadzu - IR Prestige 21). 

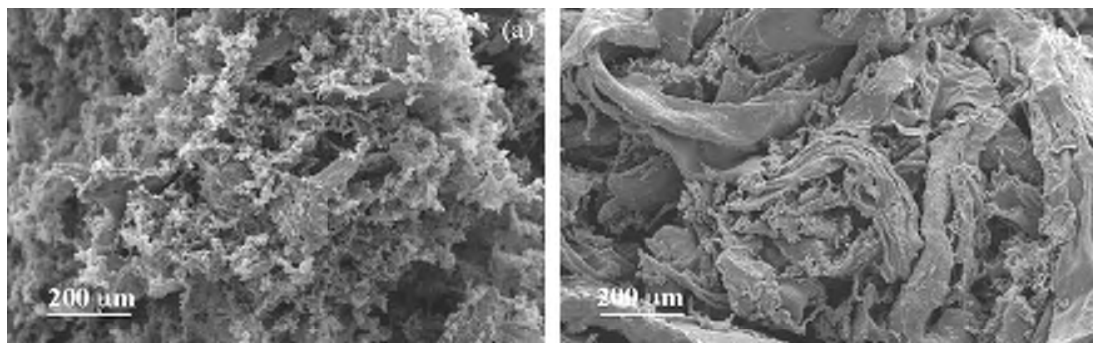

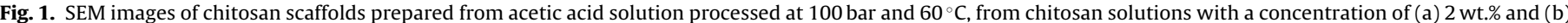
5 wt.\%.

FTIR Imaging Measurements: Imaging measurements were performed in a Perkin Elmer Spotlight 200 FTIR Microscope System. Spectra were collected in continuous scan mode (wavelength range: $4000-500 \mathrm{~cm}^{-1}$ ) over an area of $500 \mu \mathrm{m} \times 500 \mu \mathrm{m}$, at 15 scans per spectrum with a resolution of $16 \mathrm{~cm}^{-1}$.

Differencial Scanning Calorimetry: DSC experiments were carried out using a DSC Q100 equipment (TA Instruments). The experiments were conducted, under a nitrogen atmosphere, on samples (5-10 mg) packed in aluminium pans. The samples were heated in two stages at a constant heating rate of $20^{\circ} \mathrm{C} / \mathrm{min}$ from room temperature up to $200^{\circ} \mathrm{C}$, then were left at this temperature for a period of $2 \mathrm{~min}$ and cooled at the same rate to the initial temperature. At this point a 2 nd heating run was conducted.

\section{Results and discussion}

The successful preparation of 3D chitosan scaffolds using supercritical fluid technology has been described in our previous work, in which, polymeric matrixes were precipitated from acetic acid solutions, by supercritical assisted phase-inversion [28]. In the present work, two different chitosan concentrations in solution were tested, 2 and 5 wt.\%. Fig. 1 represents the scanning electron microscopy analysis of the two chitosan matrixes processed at the same operating conditions.

Scaffolds prepared from $5 \mathrm{wt}$.\% solution are less homogeneous and much more difficult to dry, as chitosan itself swells the acetic acid making it extremely difficult to remove. A more objective analysis can be carried out by micro-computed tomography ( $\mu$ $\mathrm{CT}$ ), which allows a better visualization of the inner structure of the materials as well as the determination of porosity, interconnectivity and pore size distribution. Fig. 2 shows a Micro-CT representative image of a $2 \mathrm{D}$ slice of the chitosan scaffold prepared from a 2 wt.\% solution.

Poly(L-lactic acid), PLLA, alone was also processed using the same methodology. A polymeric solution of $5 \mathrm{wt} . \%$ was precipitated and a solid membrane was collected in the bottom of the mould. Fig. 3 represents a SEM image of the PLLA processed.



Fig. 2. Micro-CT representative $2 \mathrm{D}$ images of chitosan scaffolds prepared from acetic acid solution processed at $100 \mathrm{bar}, 60^{\circ} \mathrm{C}, 2 \mathrm{wt} . \%$.

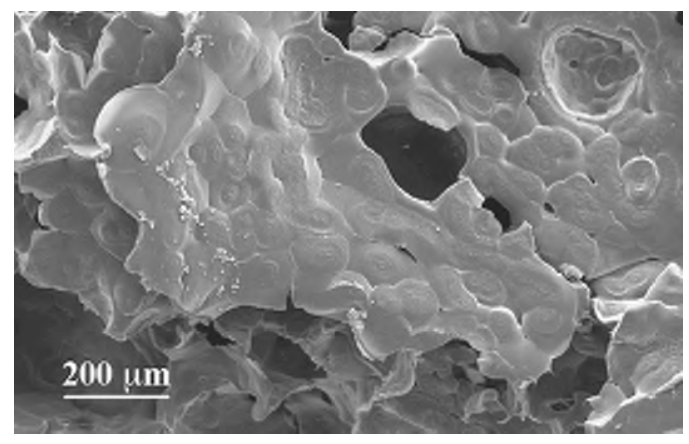

Fig. 3. SEM images of PLLA scaffolds prepared from acetic acid solution ( $5 \mathrm{wt} . \%$ ) processed at $100 \mathrm{bar}$ and $60^{\circ} \mathrm{C}$.

Processing of 3D PLLA constructs was not possible with such low polymer concentration in solution. However, the main objective of this work is to prepare novel blends containing chitosan and PLLA. For this purpose and taking into account the results obtained with pure polymers, the concentration chosen for the preparation of scaffolds from CHT:PLLA blends was 2 wt.\%. Fig. 4 shows the scanning electron microscope images of the different scaffolds processed with two different magnitudes.

From the SEM images it is possible to distinguish chitosan leafy structure, which gives support to the 3D matrix and small spheres that correspond to PLLA. These results suggest that PLLA was micronized during the phase-inversion process and particles seem to be homogeneously dispersed within the construct. The microstructure of the scaffolds were also characterized by $\mu-C T$. Table 2 presents a summary of the morphological characteristics of the CHT:PLLA matrixes produced by supercritical assisted phaseinversion.

The morphology of the scaffolds produced is very similar to the structure prepared for pure chitosan. The precipitation from an acetic acid solution leads to a bicontinuous structure. This system is characterized by a homogeneous pore size distribution with pores presenting an average size of $\sim 75 \mu \mathrm{m}$. In addition surfaces appear very rough which could also encourage cell attachment and proliferation, when aiming tissue engineering applications. These matrixes are also characterized by some interconnected pores, which on its turn can enhance the transport properties within the structure. Having in mind the particular application of tissue engi-

Table 2

Morphological characteristics of chitosan scaffolds determined by $\mu$-CT

\begin{tabular}{rll}
\hline Chitosan (wt.\%) & $\begin{array}{l}\text { Polymer concentration } \\
\text { in solution (wt.\%) }\end{array}$ & Porosity (\%) \\
\hline 100 & 5 & 10 \\
100 & 2 & 37 \\
75 & 2 & 23 \\
50 & 2 & 44 \\
25 & 2 & 88 \\
\hline
\end{tabular}



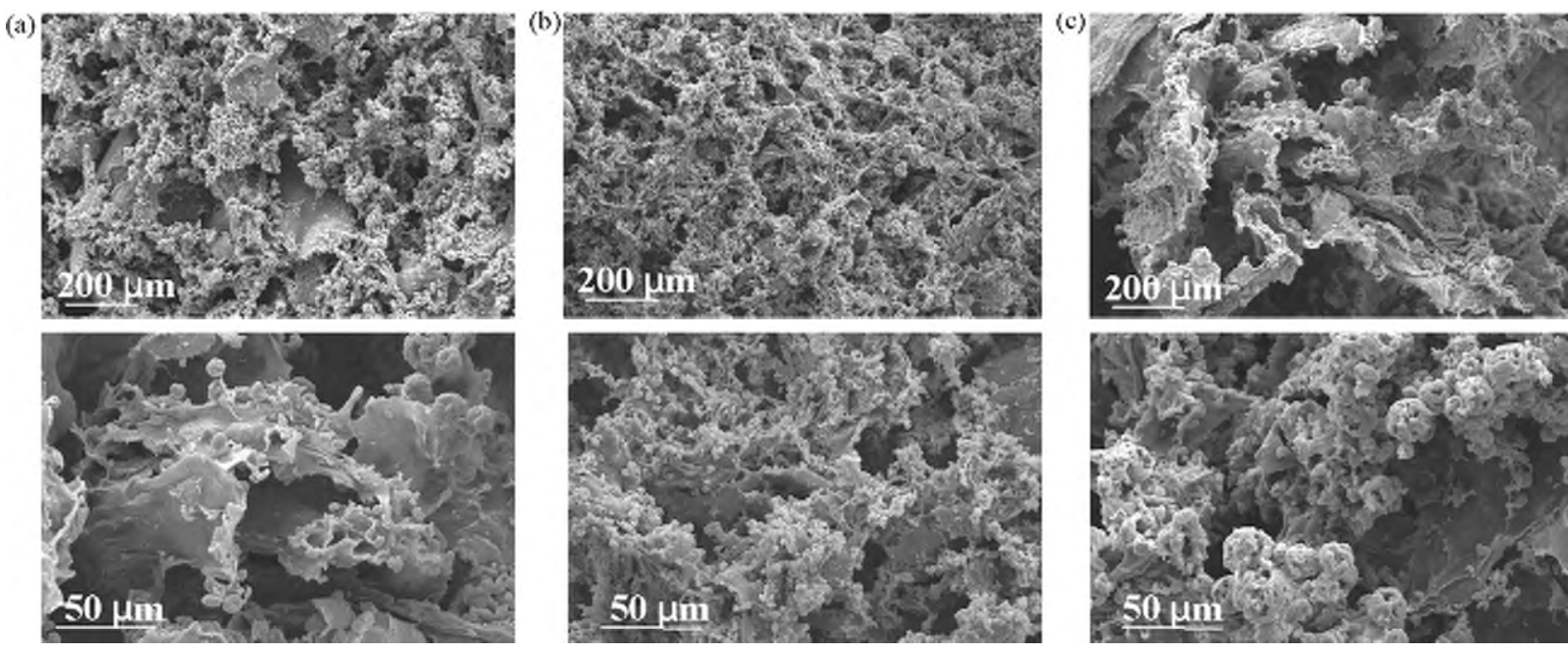

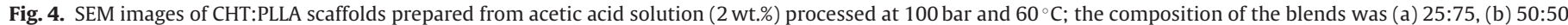
and (c) $75: 25$.

neering and the fact that ideal scaffolds for bone tissue engineering require three-dimensionally interconnected porous structures, so nutrients and oxygen can be accessible to the cells together with the elimination of cell wastes. Therefore, chitosan structures prepared from acetic acid solutions by supercritical assisted phase-inversion are potential candidates for this purpose.

When poly(L-lactic acid) is introduced in the system, the porosity of the scaffolds is drastically changed. For lower chitosan contents the matrix produced is highly porous, and the construct does not present a "compact" structure. This is also reflected on the interconnectivity of the matrixes. Regarding the CHT:PLLA 50:50 and CHT:PLLA 75:25 the differences are not noticeable. Fig. 5 represents the pore size distribution within the scaffolds prepared with different CHT:PLLA ratios.

The pore size distribution is similar for the scaffolds composed of CHT, CHT:PLLA 50:50 and CHT:PLLA 75:25. In the case of CHT:PLLA $25: 75$, the pore size distribution is very broad, for the same reasons mentioned above. The weight fraction of chitosan in this matrix is not sufficient to promote the precipitation of a uniform 3D scaffold, instead the matrix presents large pores and a very high porosity.

The presence of both polymers in the construct is confirmed by FTIR spectra of the polymeric blends processed. Fig. 6 shows the infra-red data from both pure components, chi-

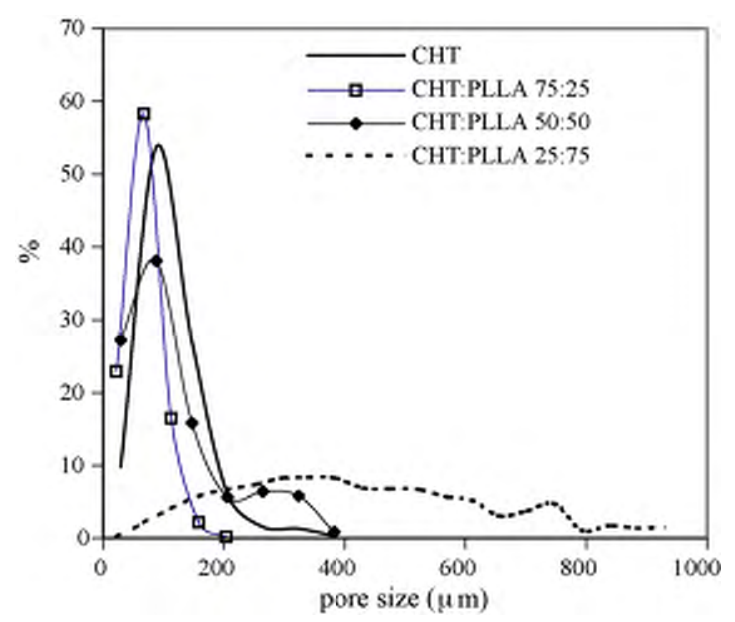

Fig. 5. Pore size distribution of the chitosan:poly(L-lactic acid) scaffolds prepared at 100 bar and $60^{\circ} \mathrm{C}$. tosan and PLLA and the mixtures CHT:PLLA 75:25; 50:50 and $25: 75$.

Chitosan and PLLA present several characteristic bands. The broad band at around $3400 \mathrm{~cm}^{-1}$ corresponds to the $\mathrm{OH}$ and $\mathrm{NH}$ stretch of chitosan. For this polymer two other strong bands are present at 1650 and $1589 \mathrm{~cm}^{-1}$ corresponding to the amide I and amide II, respectively. At $1250 \mathrm{~cm}^{-1}$, the amide III band is observed. Regarding poly(L-lactic acid) it presents at $3510 \mathrm{~cm}^{-1}$ the $\mathrm{OH}$ stretch band. At 2941 and $2993 \mathrm{~cm}^{-1}$ the $\mathrm{CH}$ and $\mathrm{CH}_{3}$ stretch bands are visible. The characteristic band of $\mathrm{C}=\mathrm{O}$ esther group is observed at $1750 \mathrm{~cm}^{-1}$.

The presence of PLLA in the porous matrix was confirmed by the SEM images and more precisely by FTIR experiments. Yet, the successful preparation of CHT:PLLA requires an homogeneous distribution of the two polymers upon the preparation of the blend. It is often difficult to determine the distribution of the polymers within a 3D matrix. In this work, FTIR imaging was performed in the scaffolds of pure CHT and the blends CHT:PLLA 50:50 and CHT:PLLA 75:25. Infra-red imaging spectroscopy is a powerful tech-

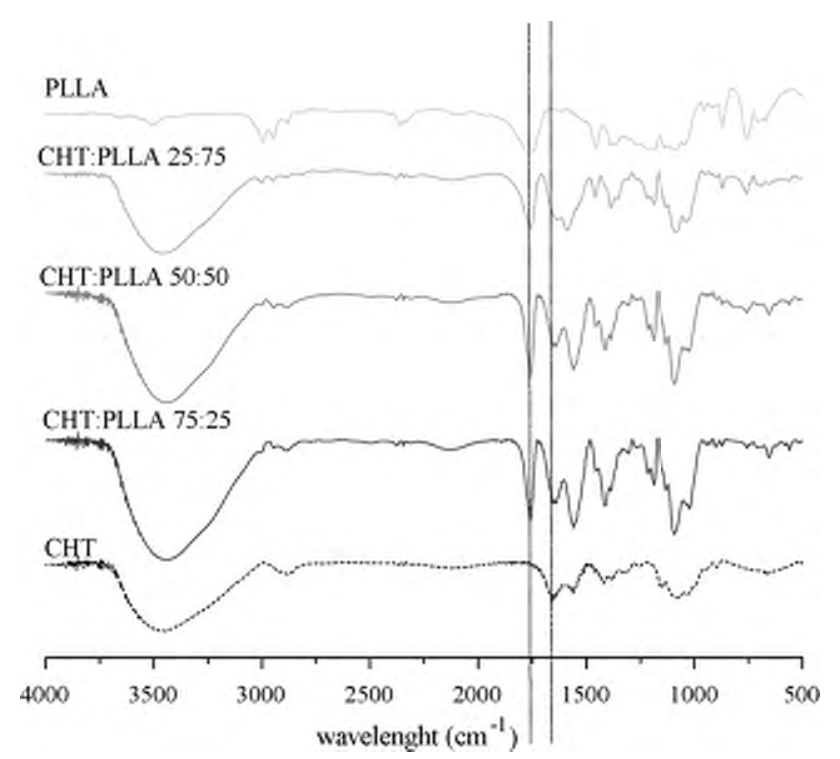

Fig. 6. FTIR spectra of the scaffolds chitosan: chitosan:poly(L-lactic acid) 75:25; chitosan:poly(L-lactic acid) 50:50; chitosan:poly(L-lactic acid) 25:75 and poly(Llactic acid). 


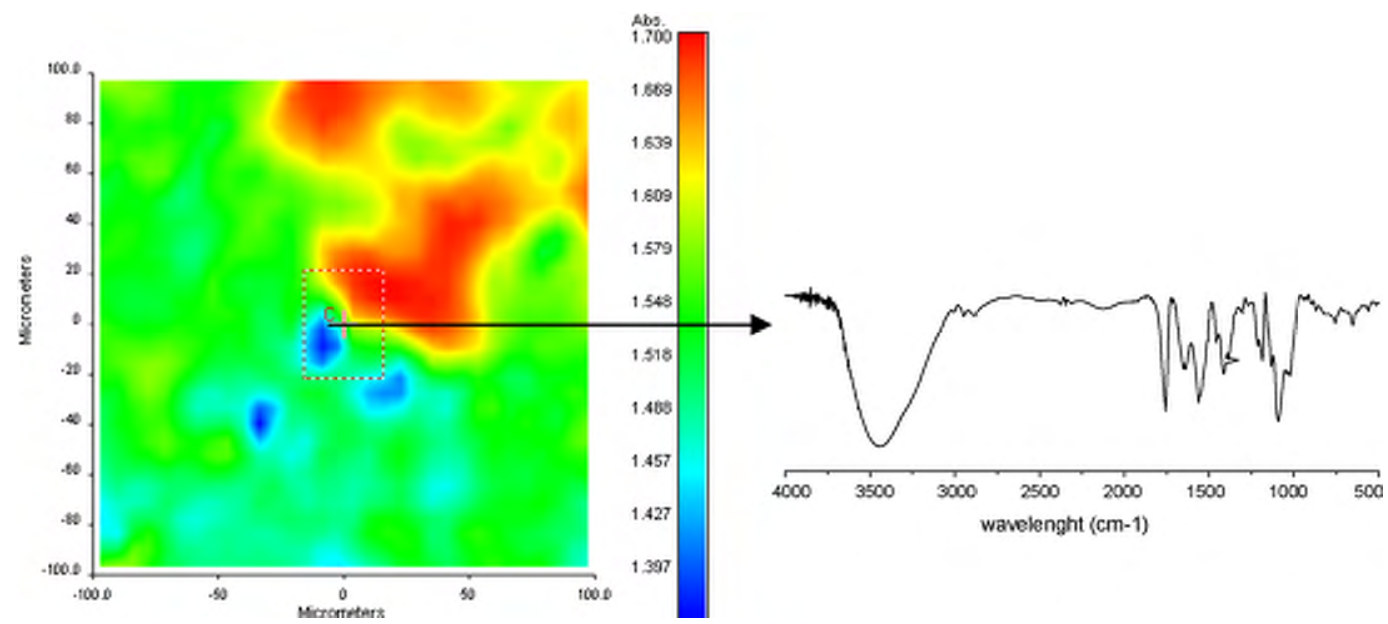

Fig. 7. FTIR spectra of (a) cross-section of $200 \mu \mathrm{m} \times 200 \mu \mathrm{m}$ of the scaffold CHT:PLLA 50:50 and (b) spectrum correspondent to point C in the construct.

nique which allows a spatial analysis of a selected area of the construct. This technique offers the possibility of mapping specific vibrational bonds for each material present in the polymeric blend. Fig. 7 represents the infra-red spectra of the scaffold CHT:PLLA 50:50.

To each data point corresponds a spectrum as the one presented in Fig. 7b. The colours describe the total absorbance of the infra-red radiation. The differences in the absorbance intensities might be due to the porosity and roughness of the surface analysed.

The surface spectra of chitosan, CHT:PLLA 50:50 and CHT:PLLA 75:25 were integrated for the amide I characteristic band of chitosan at 1650 and $1750 \mathrm{~cm}^{-1}$ band correspondent to the $\mathrm{C}=\mathrm{O}$ stretch of the ester group of PLLA (highlighted in Fig. 6). False colours were attributed to each one of the polymers, green for chitosan and red for PLLA. The band integration for the CHT:PLLA 50:50 scaffold results in the images represented in Fig. 8.

The similar intensity of the two bands indicates a good distribution of both chitosan and PLLA over the cross-section studied. The overlapping the two different chemical maps a yellow colour is obtained (Fig. 9).

(a)

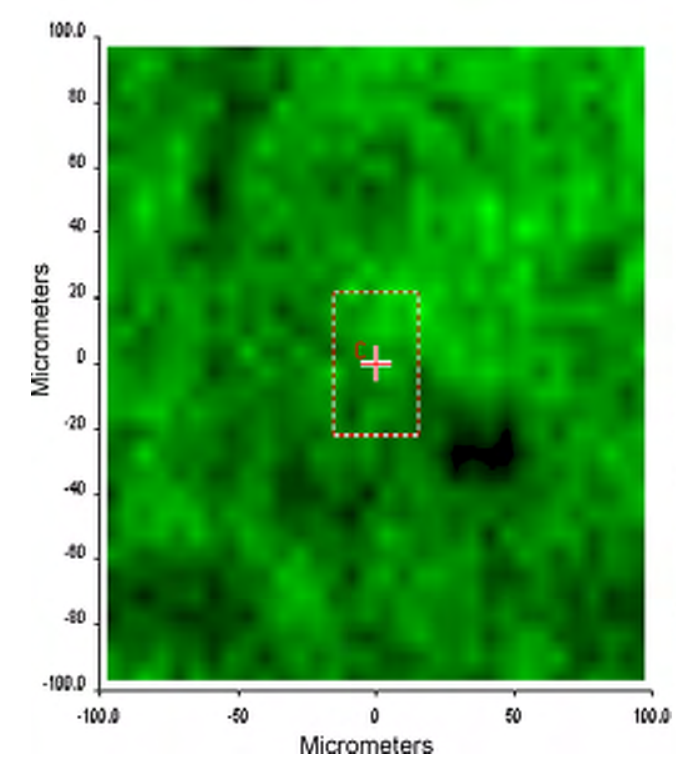

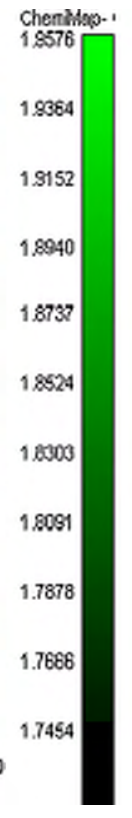

As expected the result of the integration of the pure chitosan matrix is a green map, due to the absence of the band at $1750 \mathrm{~cm}^{-1}$ (Fig. 9c). The two blends studied present a good distribution of the polymers in a $200 \mu \mathrm{m} \times 200 \mu \mathrm{m}$ area. A lower concentration of CHT in the matrix leads to a less homogeneous matrix (Fig. 9a). In this image it is possible to observe distinct areas of chitosan and PLLA, correspondent to the green and red areas, respectively. Nonetheless, we can conclude that there was no evident phase separation between the polymers in the length scale analysed.

Differential scanning calorimetry analysis provides also information on the miscibility of the chitosan and PLLA. The DSC curves of the pure polymers and of the different polymeric blends are represented in Figs. 10 and 11, which correspond to the 1st and 2nd heating run, respectively.

There are evident differences on the 1st and 2nd heating runs. The 1 st heating stage allows the evaluation of any effect of the processing. In the 2 nd scan such effects are erased and the differences among the materials are evidenced. In the 1st DSC scan of pure chitosan an endothermic transition appears at about $60-120^{\circ} \mathrm{C}$, corresponding to the release of bound water present in the chitosan (b)

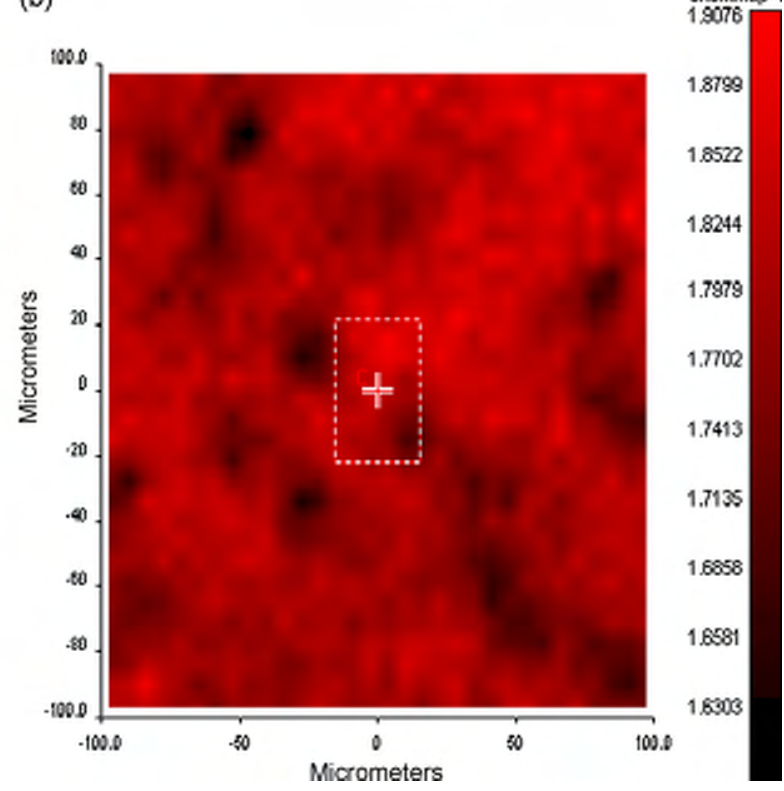

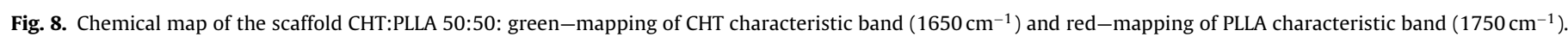
(For interpretation of the references to color in this figure legend, the reader is referred to the web version of the article.) 
(a)

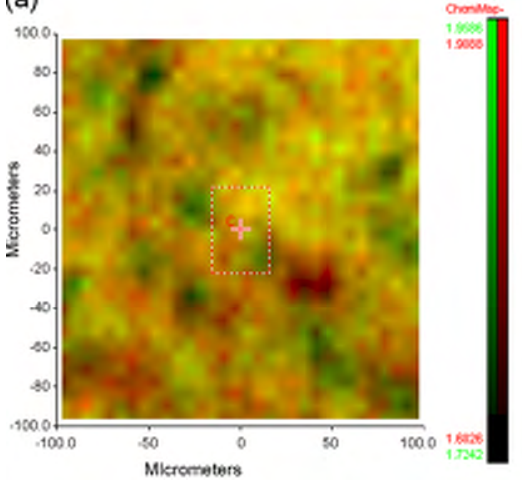

(b)

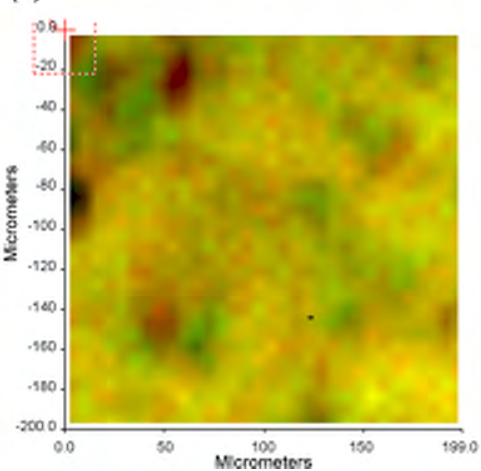

(c)

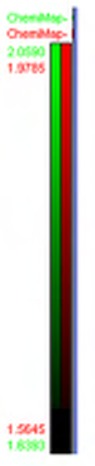

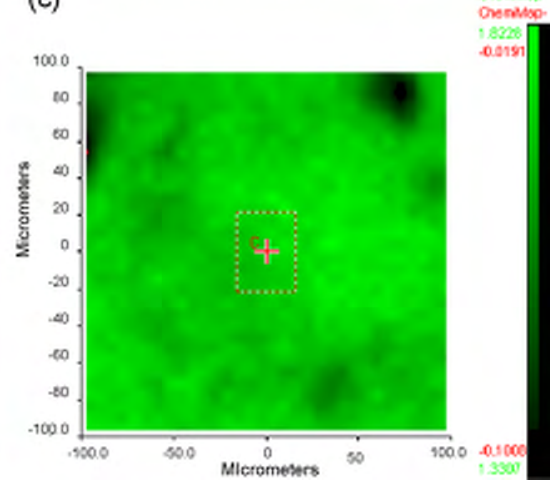

Fig. 9. IR false contour image of the scaffolds: (a) CHT:PLLA 50:50, (b) CHT:PLLA 75:25 and (c) CHT.



Fig. 10. DSC 1st heating run: (a) CHT, (b) CHT:PLLA 75:25, (c) CHT:PLLA 50:50, (d) CHT:PLLA 25:75 and (e) PLLA.

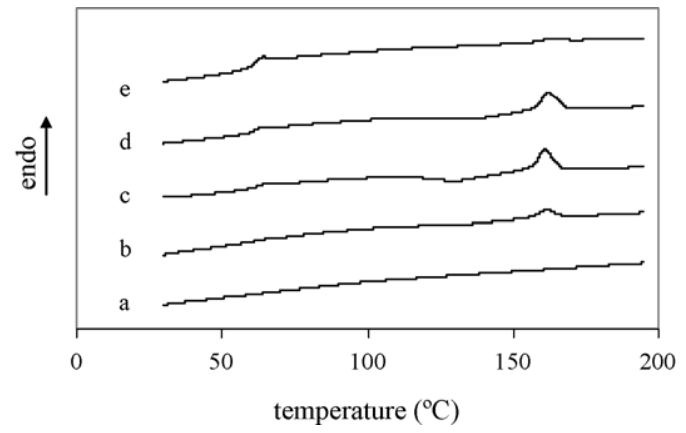

Fig. 11. DSC 2nd heating run: (a) CHT, (b) CHT:PLLA 75:25, (c) CHT:PLLA 50:50, (d) CHT:PLLA 25:75 and (e) PLLA.

matrix. As expected, this process is absent in the 2nd scan. Melting and glass transition temperature of chitosan are not detected in the temperature range studied. For these reason only thermal properties of PLLA can be evaluated. PLLA presents two endothermic transitions, which correspond to structural relaxation associated with glass transition temperature and melting point, at 59.8 and $157^{\circ} \mathrm{C}$ respectively. In the 2 nd scan the enthalpy relaxation peak is not evident, as the system had not time to undergo structural relaxation between the two scans; however the $T_{\mathrm{g}}$ is still evi-

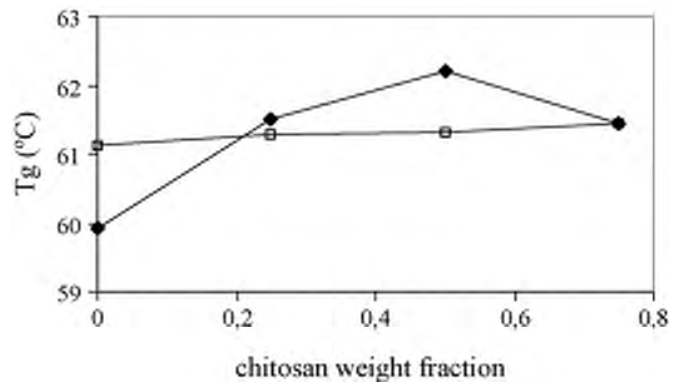

Fig. 12. Glass transition temperature of PLLA as a function of chitosan weight fraction in the blend, determined by DSC: $(\diamond) 1$ st heating run ( $\square)$ 2nd heating run.

dent by the increase in heat capacity reflected in the step on the traces.

Glass transition temperature $\left(T_{\mathrm{g}}\right)$ melting temperature $\left(T_{\mathrm{m}}\right)$ and melting enthalpy $\left(\Delta H_{\mathrm{m}}\right)$ were determined for the pure PLLA and for the different blends produced and are presented in Table 3.

The evaluation of the glass transition temperature of the polymeric blends can provide information on the miscibility of the two polymers. When two polymers are completely immiscible, two different peaks, corresponding to each $T_{\mathrm{g}}$ will appear in the DSC. On the other hand if the polymers are completely miscible a new $T_{\mathrm{g}}$ peak will be observed in between the $T_{\mathrm{g}}$ of the pure components. In the case of polymeric blends of CHT:PLLA we can infer on the miscibility of the two polymers taking into consideration the $T_{\mathrm{g}}$ of pure PLLA.

Different thermal-analysis techniques have been reported in the literature to determine the $T_{\mathrm{g}}$ of chitosan, namely dynamic mechanical analysis and DSC [32,29]. Mucha and Pawlak [33] suggested that the glass transition of pre-heated chitosan should be found in the range of $140-160^{\circ} \mathrm{C}$; however, similar DSC experiments did not present any clear change in the heat capacity in this temperature range [34]. In another work [35] $T_{\mathrm{g}}$ was identified as being $203^{\circ} \mathrm{C}$, but again the identification is not completely clear. Pizzoli et al. [36] also reported a high $T_{\mathrm{g}}$ value for chitosan, around $220^{\circ} \mathrm{C}$.

Table 3

DSC data and crystallinity of PLLA and CHT:PLLA blends prepared by supercritical assisted phase-inversion.

\begin{tabular}{|c|c|c|c|c|c|c|c|c|c|}
\hline & \multirow[t]{2}{*}{ Chitosan (wt.\%) } & \multicolumn{4}{|c|}{ 1st Heating run } & \multicolumn{4}{|c|}{ 2nd Heating run } \\
\hline & & $T_{\mathrm{g}}\left({ }^{\circ} \mathrm{C}\right)$ & $T_{\mathrm{m}}\left({ }^{\circ} \mathrm{C}\right)$ & $\Delta H_{m}(\mathrm{~J} / \mathrm{g})$ & $X(\%)$ & $T_{\mathrm{g}}\left({ }^{\circ} \mathrm{C}\right)$ & $T_{\mathrm{m}}\left({ }^{\circ} \mathrm{C}\right)$ & $\Delta H_{m}(\mathrm{~J} / \mathrm{g})$ & $X(\%)$ \\
\hline PLLA & 0 & 59.9 & 157 & 5.3 & 5.7 & 61.1 & 157 & 4.5 & 4.8 \\
\hline CHT:PLLA & 25 & 61.5 & 157 & 13.5 & 19.4 & 61.3 & 157 & 7.4 & 10.6 \\
\hline CHT:PLLA & 50 & 62.2 & 156 & 8.7 & 18.7 & 61.3 & 156 & 7.6 & 16.3 \\
\hline CHT:PLLA & 75 & 61.4 & 156 & 3.3 & 14.2 & 61.4 & 156 & 2.5 & 10.7 \\
\hline
\end{tabular}




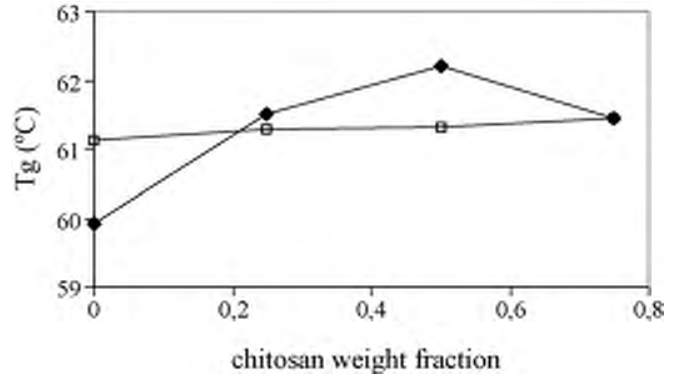

Fig. 13. Crystallinity degree of the scaffolds prepared with different chitosan weight fractions ( $)$ 1st heating run ( $\square$ ) 2nd heating run.

Fig. 12 shows the differences in glass transition temperature of the polymeric blends with increasing concentration of chitosan, for the 1 st and 2 nd heating runs.

The variation observed in the glass transition temperature, as the weight fraction of chitosan increases, towards higher values suggests that PLLA and chitosan are partially miscible. This result may indicate that interaction could occur between the two constituents at the molecular level.

The $T_{\mathrm{g}}$ of the materials is similar when obtained from the 2 nd scan. This could be a result of phase separation or other structural reorganization that occurred during the melting and recrystallization, taking place before the 2 nd heating scan.

Additionally, the crystallinity of the samples can be estimated. Crystallinity is related with the melting enthalpy following equation (1):

$X=\frac{\Delta H_{\mathrm{m}}}{\Delta H_{\mathrm{m}}^{0} \cdot w} \times 100$

where $\Delta H_{\mathrm{m}}$ is the melting enthalpy of the sample, $\Delta H_{\mathrm{m}}^{0}$ is the melting enthalpy of $100 \%$ crystalline poly(L-lactic acid) (93 J/g [37]), and $w$ is the weight fraction of PLLA in the blend, which varies from 25 to $100 \mathrm{wt} . \%$. The melting enthalpies vary between the $1 \mathrm{st}$ and 2 nd scan. This is due to the fact that the previous crystallization development occurred in different thermal environment for the two cases. In fact it was shown before that crystallinity, and even melting temperature, depend on the previous melting and crystallization conditions [38,39].

The addition of chitosan influences the crystallinity of the PLLA in the blend (Fig. 13). This can be explained by the possible interactions between the two polymers, which, in its turn, can be attributed to eventual hydrogen bonds formed between the amino group of chitosan and the carboxyl group of PLLA or between the hydroxyl group, of chitosan and the carboxyl of the polyester. Therefore, chitosan may act as a nucleation agent, enhancing the crystallization process for PLLA.

\section{Conclusions}

In this work, the feasibility of preparing porous structures of a natural based polymeric systems using supercritical fluid technology was evaluated. Supercritical assisted phase-inversion is a promising technology for the preparation of chitosan: poly(L-lactic acid) blends for tissue engineering applications.

Blends of chitosan:PLLA were processed and we can conclude that porosity is greatly influenced by the concentration of polymer in solution and on the ratio CHT:PLLA. The presence of a much higher concentration of PLLA in the blend produces structures exhibiting bigger and more heterogeneous pores.

Polymer distribution within the 3D matrix was analysed by FTIR imaging through the integration of the characteristic IR bands of chitosan and PLLA. Results suggest that no phase separation occurred during the process and PLLA is homogeneously distributed in the scaffold in a length scale of $200 \mu \mathrm{m}$. DSC analysis allowed further evaluation of the miscibility between the two polymers. Data obtained from the differential scanning calorimetry indicate a shift in the glass transition temperature of PLLA towards higher values, which points out the possible interaction of the amino group of chitosan and the carboxyl group of PLLA or between the hydroxyl group, of chitosan and the carboxyl of the polyester.

The preparation of an homogeneous structure of chitosan: poly(L-lactic acid) using a clean and environmentally friendly technology constitutes a new processing technology for the preparation of scaffolds for tissue engineering using these materials.

\section{Acknowledgement}

Ana Rita C. Duarte is grateful for financial support from Fundação para a Ciência e Tecnologia through the grant SFRH/ BPD/34994/2007.

\section{References}

[1] J.F. Mano, G.A. Silva, H.S. Azevedo, P.B. Malafaya, R.A. Sousa, S.S. Silva, L.F Boesel, J.M. Oliveira, T.C. Santos, A.P. Marques, N.M. Neves, R.L. Reis, Natural origin biodegradable systems in tissue engineering and regenerative medicine: present status and some moving trends, Journal of the Royal Society Interface 4 (17) (2007) 999-1030.

[2] N.M. Alves, J.F. Mano, Chitosan derivatives obtained by chemical modifications for biomedical and environmental applications, International Journal of Biological Macromolecules 43 (5) (2008) 401-414

[3] T.C. Santos, A.P. Marques, S.S. Silva, J.M. Oliveira, J.F. Mano, A.G. Castro, R.L. Reis In vitro evaluation of the behaviour of human polymorphonuclear neutrophils in direct contact with chitosan-based membranes, Journal of Biotechnology 132 (2) (2007) 218-226.

[4] K. Tuzlakoglu, C.M. Alves, J.F. Mano, R.L. Reis, Production and characterization of chitosan fibers and 3-D fiber mesh scaffolds for tissue engineering applications, Macromolecular Bioscience 4 (8) (2004) 811-819.

[5] M. Prabaharan, J.F. Mano, Chitosan-based particles as controlled drug delivery systems, Drug Delivery 12 (1) (2005) 41-57.

[6] J.F. Mano, G. Hungerford, J.L.G. Ribelles, Bioactive poly(L-lactic acid)chitosan hybrid scaffolds, Materials Science \& Engineering C-Biomimetic and Supramolecular Systems 28 (8) (2008) 1356-1365.

[7] M. Prabaharan, M.A. Rodriguez-Perez, J.A. de Saja, J.F. Mano, Preparation and characterization of poly(L-lactic acid)-chitosan hybrid scaffolds with drug release capability, Journal of Biomedical Materials Research Part B-Applied Biomaterials 81B (2) (2007) 427-434.

[8] J. Shi, N.M. Alves, J.F. Mano, Chitosan coated alginate beads containing poly(Nisopropylacrylamide) for dual-stimuli-responsive drug release, Journal of Biomedical Materials Research Part B-Applied Biomaterials 84B (2) (2008) 595-603.

[9] E.B. Denkbas, R.M. Ottenritte, Perspectives on: chitosan drug delivery systems based on their geometries, Journal of Bioactive Compatible Polymers 21 (2006) 351-368.

[10] H.M. Nie, L.Y. Lee, H. Tong, C.H. Wang, PLGA/chitosan composites from a combination of spray drying and supercritical fluid foaming techniques: new carriers for DNA delivery, Journal of Controlled Release 129 (3) (2008) 207-214.

[11] F.L. Mi, S.S. Shyu, Y.B. Wu, S.T. Lee, J.Y. Shyong, R.N. Huang, Fabrication and characterization of a sponge-like asymmetric chitosan membrane as a wound dressing, Biomaterials 22 (2) (2001) 165-173.

[12] K. Oungbho, B.W. Muller, Chitosan sponges as sustained release drug carriers, International Journal of Pharmaceutics 156 (2) (1997) 229-237.

[13] X. Liu, P.X. Ma, Polymeric scaffolds for bone tissue engineering, Annals of Biomedical Engineering 32 (3) (2004) 477-486.

[14] J.F. Mano, R.A. Sousa, L.F. Boesel, N.M. Neves, R.L. Reis, Bioinert, biodegradable and injectable polymeric matrix composites for hard tissue replacement: state of the art and recent developments, Composites Science and Technology 64 (6) (2004) 789-817.

[15] B.L. Seal, T.C. Otero, A. Panitch, Polymeric biomaterials for tissue and organ regeneration, Materials Science and Engineering: R Reports 34 (4-5) (2001) 147-230.

[16] X.F. Zhang, H. Hua, X.Y. Shen, Q. Yang, In vitro degradation and biocompatibility of poly(L-lactic acid)/chitosan fiber composites, Polymer 48 (4) (2007) 1005-1011.

[17] Y.P. Jiao, Z.H. Liu, C.R. Zhou, Fabrication and characterization of PLLA-chitosan hybrid scaffolds with improved cell compatibility, Journal of Biomedical Materials Research Part A 80A (4) (2007) 820-825.

[18] C. Chen, L. Dong, M.K. Cheung, Preparation and characterization of biodegradable poly(L-lactide)/chitosan blends, European Polymer Journal 41 (5) (2005) 958-966.

[19] Y. Wan, H. Wu, A.X. Yu, D.J. Wen, Biodegradable polylactide/chitosan blend membranes, Biomacromolecules 7 (4) (2006) 1362-1372. 
[20] Y. Wan, Q. Wu, S. Wang, S.M. Zhang, Z.L. Hu, Mechanical properties of porous polylactide/chitosan blend membranes, Macromolecular Materials and Engineering 292 (5) (2007) 598-607.

[21] Y.Wan, Y. Fang, H. Wu, X.Y. Cao, Porous polylactide/chitosan scaffolds for tissue engineering, Journal of Biomedical Materials Research Part A 80A (4) (2007) 776-789.

[22] O.R. Davies, A.L. Lewis, M.J. Whitaker, H. Tai, K.M. Shakesheff, S.M. Howdle, Applications of supercritical $\mathrm{CO}_{2}$ in the fabrication of polymer systems for drug delivery and tissue engineering, Advanced Drug Delivery Reviews 60 (3)(2008) 373-387.

[23] D.L. Tomasko, H.B. Li, D.H. Liu, X.M. Han, M.J. Wingert, L.J. Lee, K.W. Koelling, A review of $\mathrm{CO}_{2}$ applications in the processing of polymers, Industrial \& Engineering Chemistry Research 42 (25) (2003) 6431-6456.

[24] A.R.C. Duarte, J.F. Mano, R.L. Reis, Perspectives on: supercritical fluid technology for the preparation of 3D scaffolds for tissue engineering applications, Journal of Bioactive and Compatible Polymers 24 (2009) 385-400.

[25] A.R.C. Duarte, J.F. Mano, R.L. Reis, Supercritical fluids in biomedical and tissue engineering applications: a review, International Material Reviews 54 (4) (2009) 214-222.

[26] H. Matsuyama, A. Yamamoto, H. Yano, T. Maki, M. Teramoto, K. Mishima, K. Matsuyama, Formation of porous flat membrane by phase separation with supercritical $\mathrm{CO}_{2}$, Journal of Membrane Science 194 (2001) 157.

[27] E. Reverchon, S. Cardea, Formation of cellulose acetate membranes using a supercritical fluid assisted process, Journal of Membrane Science 240 (2004) 187.

[28] A.R.C. Duarte, J.F. Mano, R.L. Reis, Preparation of starch-based scaffolds for tissue engineering by supercritical immersion precipitation, The Journal of Supercritical Fluids 49 (2) (2009) 279-285.

[29] M. Temtem, L.M.C. Silva, P.Z. Andrade, F. dos Santos, C.L. da Silva, J.M.S. Cabral M.M. Abecasis, A. Aguiar-Ricardo, Supercritical $\mathrm{CO}_{2}$ generating chitosan devices with controlled morphology. Potential application for drug delivery and mes- enchymal stem cell culture, The Journal of Supercritical Fluids 48 (3) (2009) 269-277.

[30] A.R.C. Duarte, J.F. Mano, R.L. Reis, Chitosan scaffolds prepared by supercritical assisted phase inversion for tissue engineering applications, in: Proceedings of the 9th International Symposium on Supercritical Fluids, Arcachon, France, 2009.

[31] E. Reverchon, R. Adami, S. Cardea, G.D. Porta, Supercritical fluids processing of polymers for pharmaceutical and medical applications, The Journal of Supercritical Fluids 47 (3) (2009) 484-492.

[32] J.F. Mano, Viscoelastic properties of chitosan with different hydration degrees as studied by dynamic mechanical analysis, Macromolecular Bioscience 8 (1) (2008) 69-76.

[33] M. Mucha, A. Pawlak, Thermal analysis of chitosan and its blends, Thermochimica Acta 427 (1-2) (2005) 69-76.

[34] F.S. Kittur, K.V. Harish Prashanth, K. Udaya Sankar, R.N. Tharanathan, Characterization of chitin, chitosan and their carboxymethyl derivatives by differential scanning calorimetry, Carbohydrate Polymers 49 (2) (2002) 185-193.

[35] K. Sakurai, T. Maegawa, T. Takahashi, Glass transition temperature of chitosan and miscibility of chitosan/poly(N-vinyl pyrrolidone) blends, Polymer 41 (19) (2000) 7051-7056.

[36] M. Pizzoli, G. Ceccorulli, M. Scandola, Molecular motions of chitosan in the solid state, Carbohydrate Research 222 (1991) 205-213.

[37] E.W. Fischer, H.J. Sterzel, G. Wegner, Investigation of the structure of solution grown crystals of lactide copolymers by means of chemical reactions, Colloid \& Polymer Science 251 (11) (1973) 980-990.

[38] Y. Wang, J.L.G. Ribelles, M.S. Sanchez, J.F. Mano, Morphological contributions to glass transition in poly(L-lactic acid), Macromolecules 38 (11) (2005) 4712-4718.

[39] Y.M. Wang, J.F. Mano, Influence of melting conditions on the thermal behaviour of poly(L-lactic acid), European Polymer Journal 41 (10) (2005) 2335-2342. 